\title{
Synthesis of leucascandrolide $A^{*}$
}

\author{
Ying Wang, Jelena Janjic, and Sergey A. Kozmin $¥$ \\ Department of Chemistry, University of Chicago, 5735 South Ellis Avenue, \\ Chicago, IL 60637, USA
}

\begin{abstract}
This paper describes a convergent and stereocontrolled synthesis of leucascandrolide A, a marine natural product that exhibits potent growth inhibition of mammalian and yeast cells. The approach features a substrate-directed relay of the stereochemical information via a series of highly diastereoselective transformations. Spontaneous macrolactolization discovered during this synthetic exercise has provided an unprecedented access to this marine macrolide and demonstrates a new tactic for assembling large-ring systems based on the thermodynamic preference of hemiacetalization.
\end{abstract}

Keywords: leucascandrolide; macrolactolization; hydrosilylation; natural products; diastereocontrol.

\section{INTRODUCTION}

It was the identification of a new genus of calcareous sponges, Leucascandra caveolata, collected along the coast of New Caledonia by Pietra and coworkers, that resulted in the discovery of a new natural product designated as leucascandrolide A (1) [1]. In preliminary cell-based studies, leucascandrolide A displayed potent cytotoxicity against $\mathrm{KB}$ and $\mathrm{P} 388$ tumor cell lines $\left(\mathrm{GI}_{50} 50\right.$ and $250 \mathrm{ng} / \mathrm{ml}$, respectively) and strong growth inhibition of the animal-pathogenic yeast Candida albicans (26/40, 23/20, and $20 / 10[\mathrm{~mm}] / \mathrm{mg}$ ). Interestingly, leucascandrolide A possessed a unique architecture, which was highly unusual for metabolites produced by calcareous sponges. This discrepancy led Pietra to speculate that leucascandrolide A may have originated from a microbial organism present in L. caveolata [1]. Indeed, the samples of this sponge collected five years later did not contain any traces of leucascandrolide A, strongly suggesting the microbial origin of this natural product. While the biogenetic origin of leucascandrolide A continued to remain unknown, the efficient chemical synthesis represented the only viable option for the production of this unique natural product. Not surprisingly, the complexity of leucascandrolide A, potent cytotoxic and antifungal properties combined with the uncertainty of the biogenetic

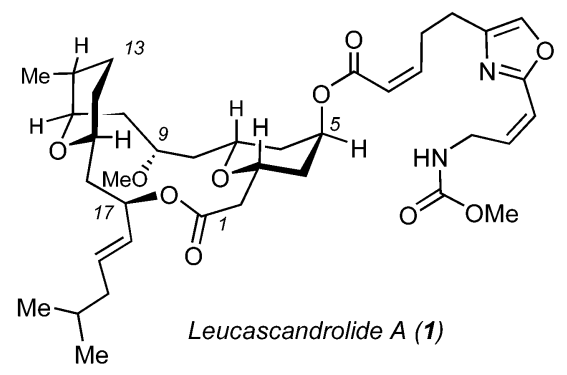

\footnotetext{
*Pure Appl. Chem. 77, 1087-1296. An issue of reviews and research papers based on lectures presented at the $15^{\text {th }}$ International Conference on Organic Synthesis (ICOS-15), held in Nagoya, Japan, 1-6 August 2004, on the theme of organic synthesis.

¥Corresponding author
} 
origin stimulated considerable synthetic interest in this target [2,3]. Herein, we present a detailed account of our synthetic studies, which resulted in the development of a convergent, stereocontrolled, and efficient synthesis of leucascandrolide A [4].

\section{STRATEGY}

Our objective was to develop a practical synthesis of leucascandrolide A, which would enable preparation of a substantial amount of the natural product and a range of unnatural analogs for subsequent biological studies. The initial disconnection entailed a convergent dissection of the target at the $\mathrm{C}_{5}$ using a Mitsunobu transform to reveal macrolide 2 and oxazole-bearing subunit $\mathbf{3}$ (Scheme 1). The macrolide 2 was envisioned to originate from the simplified fragments $4, \mathbf{5}$, and $\mathbf{6}$. The chirality of the pyran fragment 5 would provide a foundation for incorporation of the remaining stereogenic centers via a series of diastereoselective transformations as depicted in Scheme 1. The synthesis of the oxazole-containing fragment 3 presented several additional challenges including incorporation of the two required cis-alkenes and a properly substituted oxazole moiety. Construction of the oxazole precursor 7 relied on the condensation of Rh carbene $\mathbf{9}$ with nitrile $\mathbf{8}$.

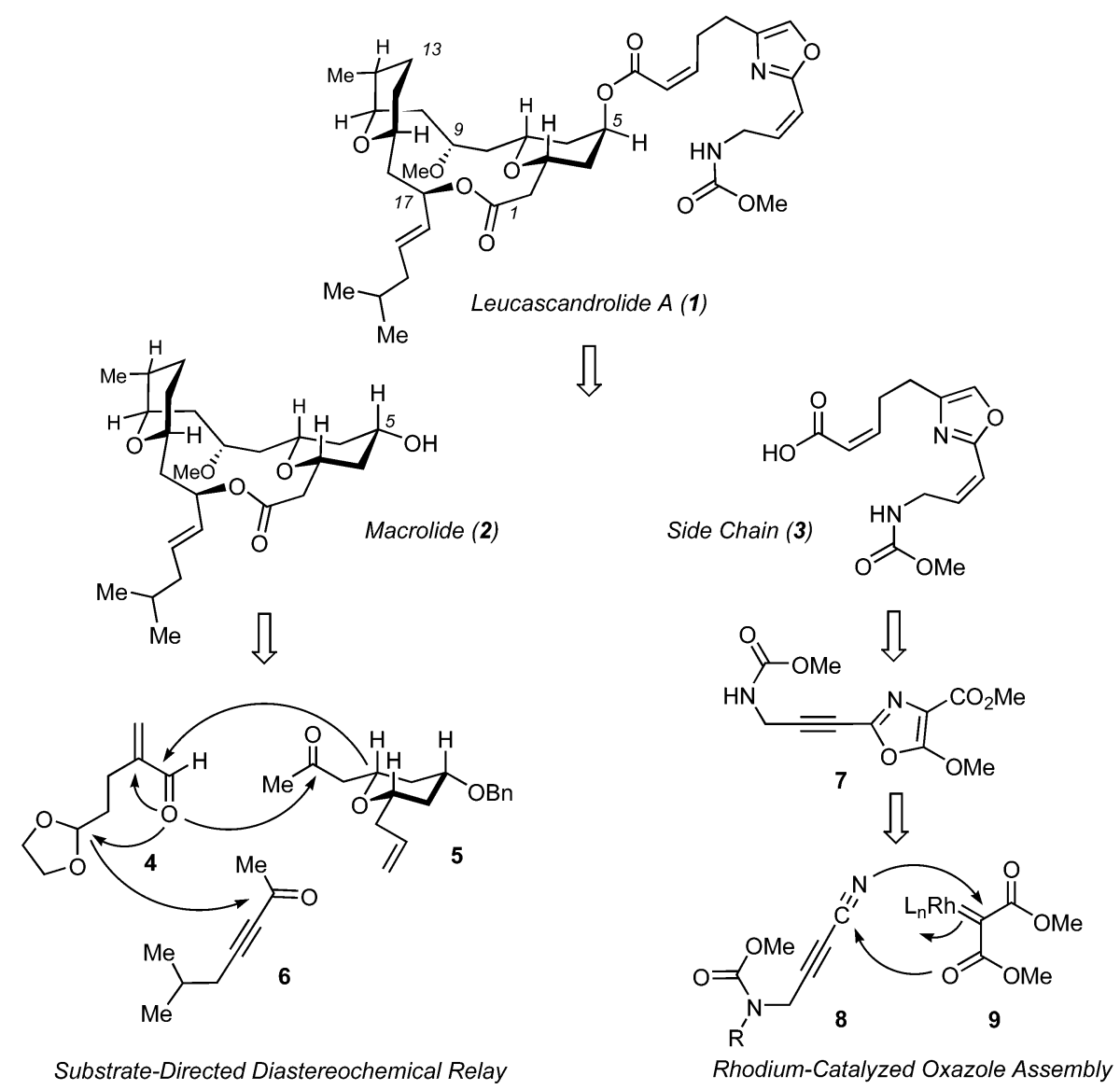

Scheme 1 


\section{SYNTHESIS OF THE MACROLIDE SUBUNIT}

Our strategy for macrolide assembly was designed to exploit the substrate-directed diastereoselection in establishing all of the stereogenic centers of leucascandrolide A. The first critical step in the successful execution of this approach was the efficient and diastereoselective assembly of trisubstituted pyran 5. The Prins reaction offered an ideal solution for stereocontrolled construction of this fragment [5].

\section{Prins desymmetrization}

The synthesis began with the vinylogous transesterification of 4-methoxy-3-butenone (10) with heptadienol 11 to afford the Prins cyclization precursor in $92 \%$ yield (Scheme 2) [6]. Treatment of the vinylogous ester 12 with TFA at $5{ }^{\circ} \mathrm{C}$ [7], followed by in situ hydrolysis of the trifluoroacetate, afforded the desired Prins cyclization product with $92: 8$ diastereoselection at the $\mathrm{C}_{5}$. Acid-catalyzed benzylation furnished ketone 6, completing the construction of first required fragment in 3 steps and $50 \%$ overall yield. The high diastereocontrol achieved at the Prins desymmetrization stage provided another illustration of the efficiency of this tactic for rapid and stereocontrolled tetrahydropyran synthesis.

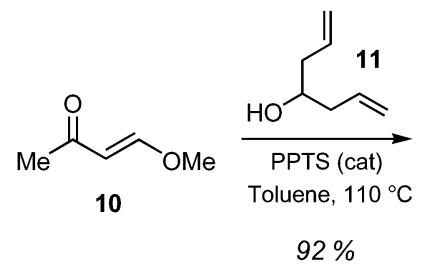<smiles>C=CCC(CC=C)O/C=C/C(C)=O</smiles>

12

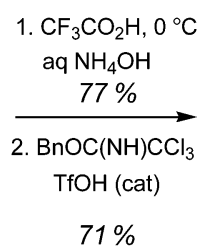

$71 \%$

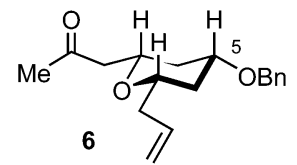

diastereoselection: 92:8

Scheme 2

\section{1,5-Anti-selective aldol condensation}

Based on the pioneering work by Paterson [8] and Evans [9], boron-enolate aldol condensation of ketone $\mathbf{6}$ with aldehyde $\mathbf{4}$ was expected to deliver the desired anti-stereochemical relationship between the newly created $\mathrm{C}_{11}$-hydroxyl and $\mathrm{C}_{7}$-alkoxy groups (Scheme 3 ). Indeed, generation of the boron enolate from ketone 6 , followed by addition of the aldehyde at $-78{ }^{\circ} \mathrm{C}$, gave hydroxy ketone $\mathbf{1 3}$ in $85 \%$ yield as a single diastereomer. Subsequent $\mathrm{SmI}_{2}$-mediated ketone reduction [10], followed by methylation and $\mathrm{LiAlH}_{4}$ reduction of the acetate, delivered alcohol 14 .

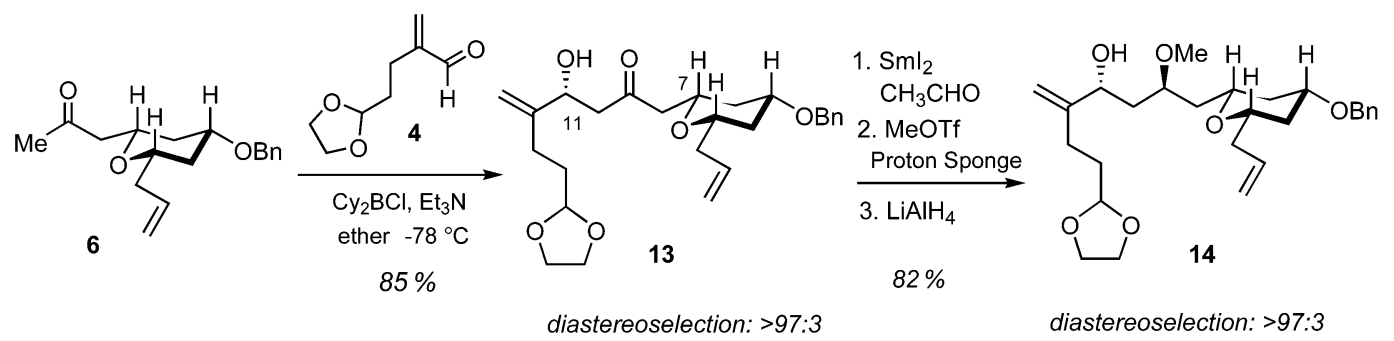

Scheme 3 


\section{Chemoselective Pt-catalyzed hydrosilylation}

The next synthetic challenge entailed a chemoselective and diastereocontrolled installation of the $\mathrm{C}_{12}$ stereogenic center (Scheme 4). Aiming at selective hydrogenation of the $\mathrm{C}_{12}$ alkene, we initially examined several established hydoxyl-directed hydrogenation methods. However, this tactic proved to be unsuccessful for achieving high levels of diastereoselection and chemocontrol. Thus, we turned our attention to the Tamao hydrosilylation method [11]. Indeed, silylation of the alcohol $\mathbf{1 4}$ with $\left(\mathrm{Me}_{2} \mathrm{HSi}\right)_{2} \mathrm{NH}$, followed by exposure of the resulting silyl ether to the Pt catalyst, delivered the desired silacyle $\mathbf{B}$ (dr 87:13) without any detectable hydrosilylation of the $\mathrm{C}_{1}$ alkene. Protodesilylation (TBAF, DMF, $50{ }^{\circ} \mathrm{C}$ ) [12] afforded the fully elaborated $\mathrm{C}_{1}-\mathrm{C}_{15}$ subunit of leucascandrolide A $\mathbf{1 5}$ (85\%, 2 steps). The outcome of the intramolecular hydrosilylation can be rationalized by considering minimization of the $A_{1,2}$ strain between $R_{1}$ and $R_{2}$ in the conformer $\mathbf{A}$, favoring the delivery of the hydride from the bottom face to give cis-substituted siloxane $\mathbf{B}$, which upon final protodesilylation of the $\mathrm{O}-\mathrm{Si}$ and $\mathrm{C}-\mathrm{Si}$ bonds furnished the desired alcohol $\mathbf{C}$.

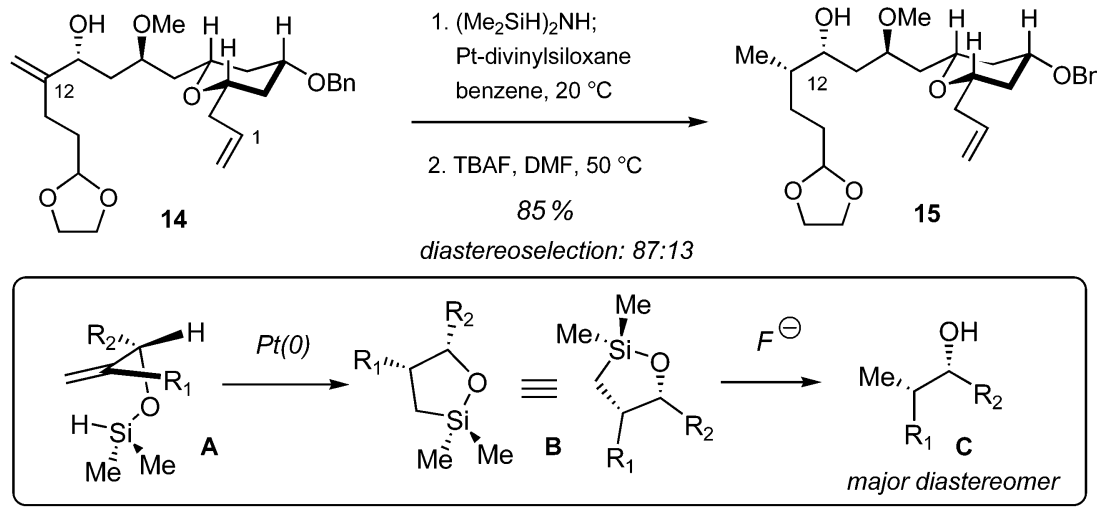

\section{Scheme 4}

\section{C-Glycosidation}

For the installation of the $\mathrm{C}_{15}$ and $\mathrm{C}_{17}$ stereogenic centers, we initially examined a route based on 1,3-anti-selective diastereoselective alkynylation of aldehyde 18, which was prepared by dioxolane removal, acetylation of the resulting lactol, followed by $C$-glycosidation with enol silane $\mathbf{1 7}$.

Treatment of aldehyde 18 with alkynyl stannane 19 in the presence of $\mathrm{EtAlCl}_{2}$ successfully accomplished the construction of the required $\mathrm{C}-\mathrm{C}$ bond with $\mathrm{dr}$ 80:20. While predominant 1,3-anti-induction was expected [13], the major product of this reaction was deduced unambiguously to be the undesired diastereomer resulting from 1,3-syn-selective addition. This result was particularly puzzling in light of the independent studies by Rychnovsky and coworkers [3a], who observed the predominant formation of the 1,3-anti-addition product in a structurally related system. Our alternative tactic involved diastereoselective reduction of the ynone 22, which was successfully constructed by $C$-glycosidation of acetate 16 with enol silane 21 (Scheme 5). Indeed, we found that L-selectride reduction (67:33 dr) afforded the desired diastereomeric alcohol 23 in $65 \%$ isolated yield. The minor diastereomer was readily converted to the requisite alcohol $\mathbf{2 3}$ via a one-pot Mitsunobu esterification-hydrolysis protocol. Subsequent alkene dihydroxylation and Red-Al alkyne reduction accomplished chemoselective conversion of alcohol 23 to triol 24. 


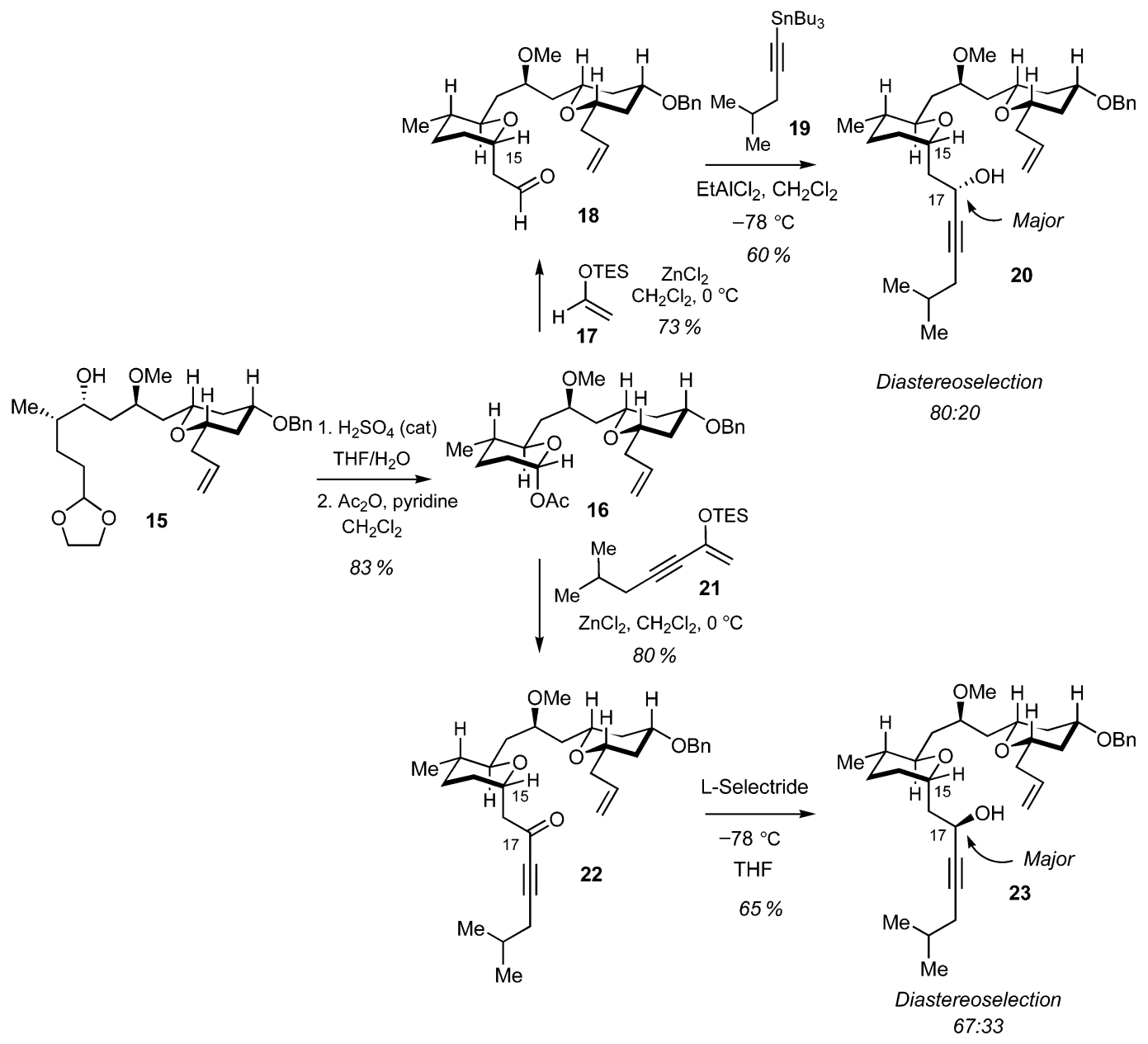

Scheme 5

\section{Spontaneous macrolactolization}

Aiming at conversion of triol $\mathbf{2 4}$ to the corresponding hydroxy aldehyde via oxidative cleavage of the vicinal diol moiety, the triol was subjected to $\mathrm{Pb}(\mathrm{OAc})_{4}$ (Scheme 6). Unexpectedly, this transformation afforded lactol 25 as a single diastereomer in $92 \%$ isolated yield, corresponding to a remarkable spontaneous intramolecular macroacetalization of the intermediate hydroxy aldehyde. Supported by double quantum filtered (DQF) correlation spectroscopy (COSY) and nuclear Overhauser enhancement spectroscopy (NOESY) experiments, conformational analysis of the lactol revealed the intramolecular hydrogen bonding motif connecting the $\mathrm{C}_{1}-\mathrm{OH}$ and $\mathrm{C}_{3}-\mathrm{O}-\mathrm{C}_{7}$ pyran. In addition to providing the assignment of the relative configuration of the $\mathrm{C}_{1}$ stereogenic center, this study revealed that the intramolecular hydrogen bonding provided additional stabilization for the thermodynamically favored hemiacetal formation. 

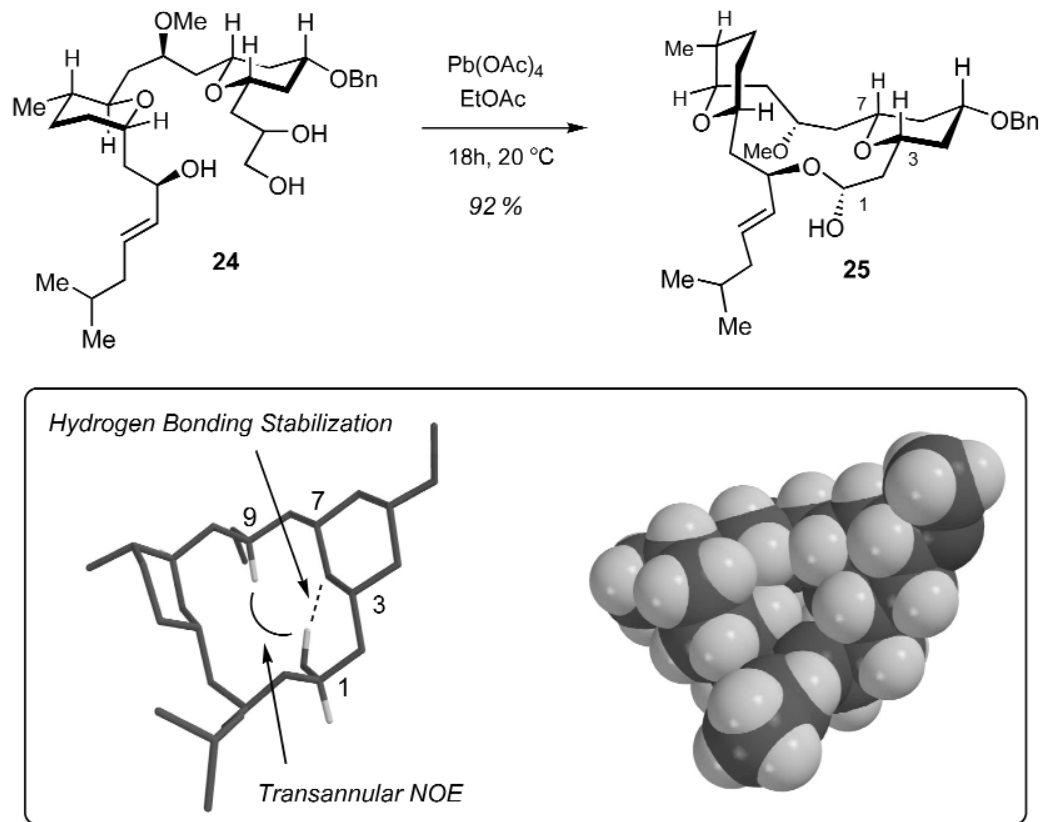

Scheme 6

Subjection of lactol 25 to pyridinium chlorochromate oxidation in $\mathrm{CH}_{2} \mathrm{Cl}_{2}$ gave the corresponding lactone in $85 \%$ yield (Scheme 7), providing further evidence of the unusual thermodynamic stability of this 14-membered macrolactol. Oxidative removal of the benzyl ether with DDQ [14] completed the synthesis of the macrolide subunit of leucascandrolide A (2), which corresponded to a 17-step longest linear sequence.
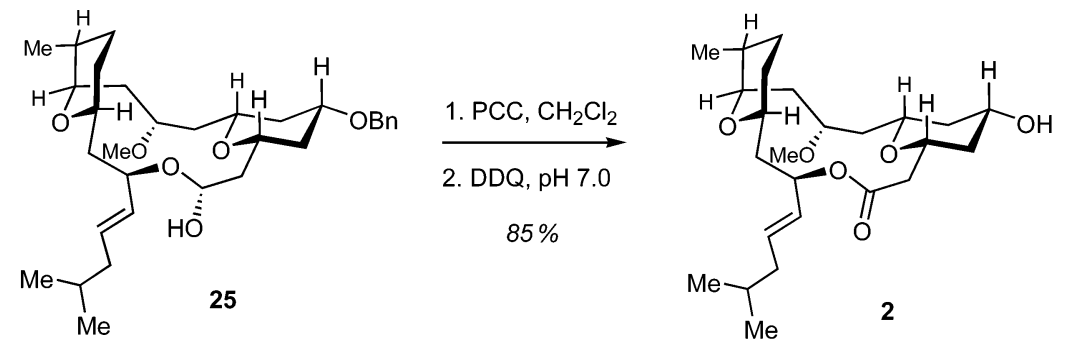

Scheme 7

\section{SYNTHESIS OF THE OXAZOLE SUBUNIT}

Construction of the oxazole-bearing subunit commenced with a cyanation of an appropriate terminal alkyne. Summarized in Table 1, our studies revealed that TsCN proved to be the most effective reagent for this transformation [15]. Interestingly, the best results were achieved when this reagent was added as a solid to a solution of lithium acetylide at $-78^{\circ} \mathrm{C}$. While TIPS protection of the carbamate was required, this protecting group could be introduced in a one-pot protocol. 
Table 1 Cyanation of terminal alkynes.

\begin{tabular}{|c|c|c|c|}
\hline \multirow[b]{2}{*}{ Entry } & \multirow{2}{*}{$\sqrt[R]{=}$} & ranation & \multirow[b]{2}{*}{ Yield, \% } \\
\hline & & Conditions & \\
\hline 1 & OTBS & CuCN, TMSOOMTS & 20 \\
\hline 2 & OTBS & $n$-BuLi, ImidCN & 18 \\
\hline 3 & OTBS & $n$-BuLi, PhOCN & 40 \\
\hline 4 & $\mathrm{NHCO}_{2} \mathrm{Me}$ & $n$-BuLi, PhOCN & 0 \\
\hline 5 & $\mathrm{~N}$ (TIPS) $\mathrm{CO}_{2} \mathrm{Me}$ & $n$-BuLi, PhOCN & 0 \\
\hline 6 & $\mathrm{~N}$ (TIPS) $\mathrm{CO}_{2} \mathrm{Me}$ & $n$-BuLi, TsCN & 51 \\
\hline 7 & $\mathrm{~N}$ (TIPS) $\mathrm{CO}_{2} \mathrm{Me}$ & $n$-BuLi, TsCN (solid) & 90 \\
\hline
\end{tabular}

Assembly of the oxazole subunit was designed to probe the participation of alkynyl nitriles in the metal-catalyzed condensation with diaza carbonyl compounds. The best results were achieved using the Helquist protocol [16] employing $5 \mathrm{~mol} \%$ of $\mathrm{Rh}_{2}(\mathrm{OAc})_{4}$, which afforded oxazole 27 in $60 \%$ yield after protodesilylation. Subsequent reduction of the methoxy oxazole moiety with 3 equiv of super-hydride delivered the requisite alcohol 29. Interestingly, the use of a stoichiometric amount of super-hydride afforded ester 28 in $64 \%$ yield.

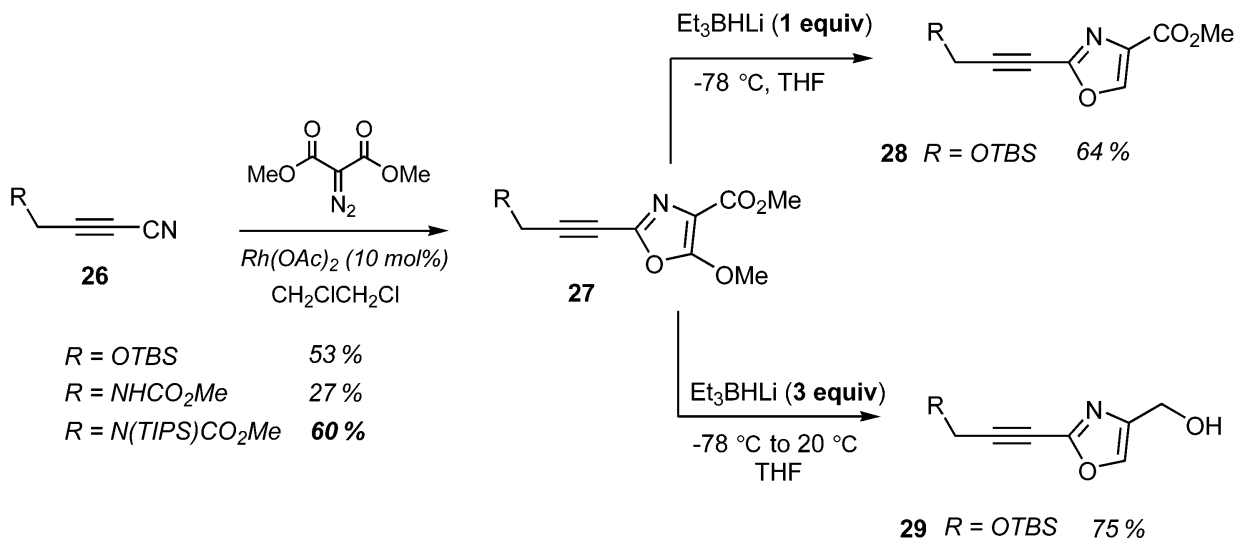

Scheme 8

Final elaboration of the carbamate 7 to the oxazole-containing subunit of leucascandrolide A is depicted in Scheme 9. The sequence began with Lindlar hydrogenation of the alkyne, followed by super-hydride reduction and bromination of the resulting alcohol. Bromide $\mathbf{3 0}$ was next employed for the alkylation of lithium enolate of imine $\mathbf{3 1}$ to afford a two-carbon extended aldehyde. Subsequent $Z$-selective olefination [17] and saponification completed the assembly of the side-chain subunit $\mathbf{3}$ (8 steps, $Z: E=92: 8$ ) 


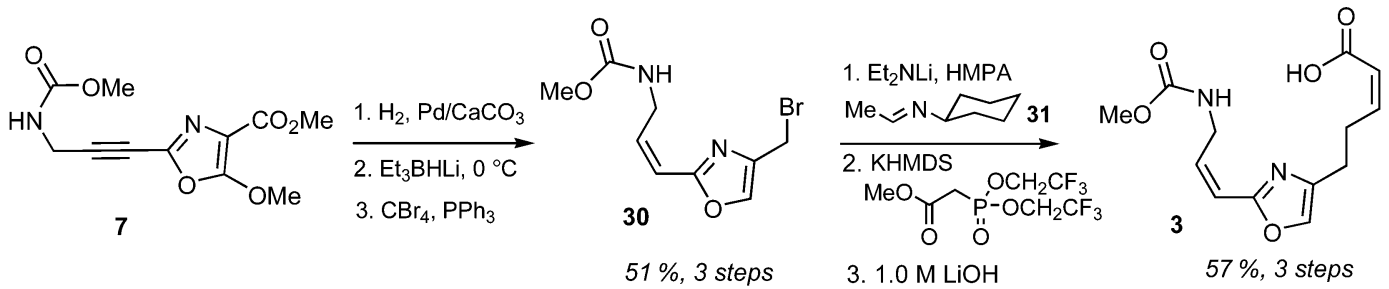

Scheme 9

\section{END GAME}

Our end game was designed to achieve the union of the fully elaborated macrolide and side-chain subunits in a single operation using Mitsunobu esterification, which would correctly establish the relative stereochemistry at the $\mathrm{C}_{5}$. The caveat was the significant degree of steric congestion at the reaction site. Following extensive model studies, we developed an efficient protocol for the final Mitsunobu condensation of alcohol 2 with acid 3 to afford the final target 1 directly in $78 \%$ yield. $500 \mathrm{MHz}{ }^{1} \mathrm{H}$ NMR and $125 \mathrm{MHz}{ }^{13} \mathrm{C}$ NMR spectra of synthetic leucascandrolide A were in excellent agreement with those reported in the literature. Furthermore, using an AD-H chiral stationary phase, we developed an effective high-performance liquid chromatography (HPLC) separation protocol, which enabled efficient access to both enantiomers of leucascandrolide A, which are currently evaluated in our laboratory in a number of mammalian and yeast cell-based cytotoxicity assays.

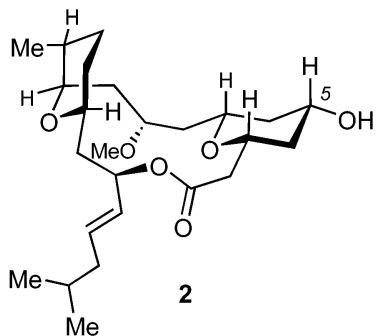

Scheme 10

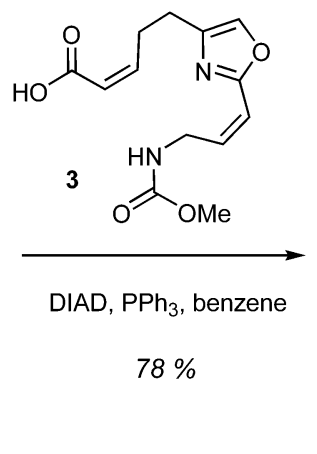

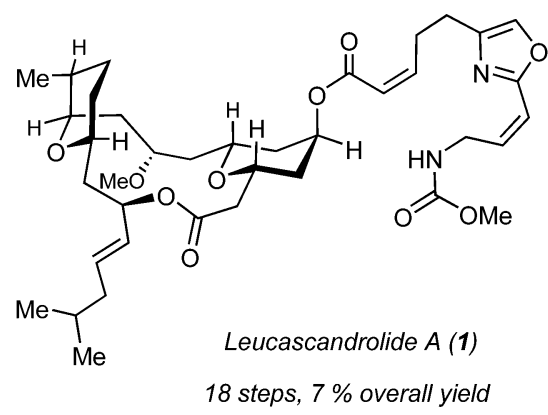

In closing, we have developed a practical synthesis of leucascandrolide A, which provided a fully synthetic access to the natural product in 18 steps from commercially available precursors. The synthesis featured an efficient substrate-directed diastereochemical relay, and the spontaneous macrolactolization, which demonstrated the possibility of assembling large-ring systems based on the thermodynamic preference of hemiacetalization.

\section{ACKNOWLEDGMENTS}

This research was supported by the National Institute of Health (National Cancer Institute, R01 CA93457). We are also grateful to the Alfred P. Sloan Foundation, Dreyfus Foundation, Amgen Inc., and GlaxoSmithKline for additional financial support of our research program. 


\section{REFERENCES}

1. M. D’Ambrosio, A. Guerriero, C. Debitus, F. Pietra. Helv. Chim. Acta 79, 51-60 (1996).

2. For syntheses of leucascandrolide A, see: (a) K. R. Hornberger, C. L. Hamblett, J. L. Leighton. J. Am. Chem. Soc. 122, 12894-12895 (2000); (b) I. Paterson and M. Tudge. Angew. Chem., Int. Ed. 42, 343-346 (2003); (c) I. Paterson and M. Tudge. Tetrahedron 59, 6833-6839 (2003); (d) D. R. Williams, S. Patnaik, S. V. Plummer. Org. Lett. 5, 5035-5038 (2003).

3. For syntheses of the leucascandrolide A macrolide subunit, see: (a) D. J. Kopecky and S. D. Rychnovsky. J. Am. Chem. Soc. 123, 8420-8421 (2001); (b) P. Wipf and J. T. Reeves. Chem. Commun. 2066-2067 (2002); (c) A. Fettes and E. M. Carreira. Angew. Chem., Int. Ed. 41, 4098-4101 (2002); (d) A. Fettes and E. M. Carreira. J. Org. Chem. 68, 9274-9283 (2003); (e) D. R. Williams and S. Patnaik. Angew. Chem., Int. Ed. 42, 3934-3938 (2003); (f) M. T. Crimmins and P. Siliphalvanh. Org. Lett. 5, 4641-4644 (2003).

4. For our preliminary communications, see: (a) S. A. Kozmin. Org. Lett. 3, 755-758 (2001); (b) Y. Wang, J. Janjic, S. A. Kozmin. J. Am. Chem. Soc. 124, 13670-13671 (2002).

5. For reviews and leading references, see (a) D. R. Adams, S. P. Bhatnagar. Synthesis 661-672 (1977); (b) B. B. Snider. In Comprehensive Organic Synthesis, Vol. 2, B. M. Trost, I. Fleming, C. H. Heathcock (Eds.), pp. 527-561, Pergamon Press, New York (1991); (c) J. Yang, G. S. Viswanathan, C. J. Li. Tetrahedron Lett. 40, 1627-1630 (1999); (d) M. Cloninger and L. E. Overman. J. Am. Chem. Soc. 121, 1092-1093 (1999); (e) S. D. Rychnovsky and C. R. Thomas. Org. Lett. 2, 1217-1219 (2000).

6. S. J. Danishefsky, M. Bednarski, T. Izawa, C. Maring. J. Org. Chem. 49, 2290-2292 (1984).

7. C. Nussbaumer and G. Frater. Helv. Chim. Acta 70, 396-401 (1987).

8. I. Paterson, K. R. Gibson, R. M. Oballa. Tetrahedron Lett. 37, 8585-8588 (1996).

9. (a) D. A. Evans, P. J. Coleman, B. Côté. J. Org. Chem. 62, 788-789 (1997); (b) D. A. Evans, B. Côté, P. J. Coleman, B. T. Connell. J. Am. Chem. Soc. 125, 10893-10898 (2003).

10. D. A. Evans and A. H. Hoveyda. J. Am. Chem. Soc. 112, 6447-6449 (1990).

11. (a) K. Tamao, T. Nakajima, R. Sumiiya, H. Arai, N. Higuchi, Y. Ito. J. Am. Chem. Soc. 108, 6090-6093 (1986); (b) K. Tamao, T. Yamauchi, Y. Ito. Chem Lett. 171-174 (1987); (c) K. Tamao, Y. Nakagawa, Y. Ito. Organometallics 12, 2297-2308 (1993).

12. M. R. Hale and A. H. Hoveyda. J. Org. Chem. 57, 1643-1645 (1992).

13. D. A. Evans, D. P. Halstead, B. D. Allison. Tetrahedron Lett. 40, 4461-4462 (1999).

14. (a) Y. Oikawa, T. Yoshioka, O. Yonemitsu. Tetrahedron Lett. 23, 885-888 (1982); (b) N. Ikemoto and S. L. Schreiber. J. Am. Chem. Soc. 114, 2524-2536 (1992).

15. (a) For cyanation of alkynyl zincs, see: I. Klement, K. Lennick, C. E. Tucker, P. Knochel. Tetrahedron Lett. 34, 4623-4626 (1993). For cyanation of lithium enolates, see: D. Kahne and D. B. Collum. Tetrahedron Lett. 22, 5011-5014 (1981).

16. (a) R. D. Connell, F. Scavo, P. Helquist, B. Åkermark. Tetrahedron Lett. 27, 5559-5562 (1986); also see (b) M. P. Doyle. Chem. Rev. 86, 919-939 (1986) and references cited therein.

17. W. C. Still and C. Gennari. Tetrahedron Lett. 24, 4405-4408 (1983). 